
ПРЕДСЕРДИЙ С ПОМОЩЬЮ КРИОМОДИФИКАЦИИ ОПЕРАЦИИ «ЛАБИРИНТ ПОСЛЕ НЕЭФФЕКТИВНОЙ ТОРАКОСКОПИЧЕСКОЙ ИЗОЛЯЦИИ ЛЕГОЧНЫХ ВЕН И РАДИОЧАСТОТНОЙ АБЛАЦИИ КАВАТРИКУСПИДАЛЬНОГО ПЕРЕШЕЙКА

Тип статьи: клинический случай

\author{
Л.А. Бокерия, С.Ю. Сергуладзе, Б.И. Кваша, Д.Я. Хинчагов \\ ФГБУ «Национальный медицинский исследовательский центр сердечно-сосудистой хирургии \\ им. А.Н. Бакулева» (директор - академик РАН и РАМН Л.А. Бокерия) Минздрава России, \\ Рублевское ш., 135, Москва, 121552, Российская Федерация
}

Бокерия Лео Антонович, доктор мед. наук, профессор, академик РАН и РАМН, директор Центра; Сергуладзе Сергей Юрьевич, доктор мед. наук, ст. науч. сотр., зам. заведующего отделением; Кваша Борис Игоревич, канд. мед. наук, мл. науч. сотр., E-mail: Boris_mma@mail.ru; Хинчагов Джумбер Яковлевич, канд. мед. наук, врач - анестезиолог-реаниматолог

\begin{abstract}
Представлено клиническое наблюдение пациента с длительно персистирующей фибрилляцей предсердий (ФП). В данном случае альтернативные хирургические методы лечения ФП, такие как интервенционная катетерная аблация и минимально инвазивная торакоскопическая аблация, оказались неэффективными. В настоящее время эти методики широко применяются для нефармакологического лечения медикаментозно резистентной ФП. По данным мировой литературы, стабильный синусовый ритм после катетерных процедур отмечается у 61-89\% пациентов на фоне приема ранее неэффективной антиаритмической терапии. Эффективность торакоскопической операции у пациентов с пароксизмальной формой ФП составляет 83-89\%, что сопоставимо с результативностью катетерных методик. Недостатком торакоскопического подхода является возможность нанесения аблационных линий только в левом предсердии. В последнее время к торакоскопической операции добавляют интервенционную процедуру в правом предсердии, что делает ее более эффективной. К сожалению, данная схема операций не способна обеспечить свободу от ФП на длительное время всем пациентам. Особенностью описанного клинического случая является радикальное эффективное устранение медикаментозно резистентной ФП, ранее безуспешно леченной с применением интервенционных и катетерных методик, после проведения криомодификации операции «Лабиринт» на открытом сердие.
\end{abstract}

Ключевые слова: фибрилляция предсердий; операция «Лабиринт»; радиочастотная аблация, мини-инвазивная торакоскопическая хирургия.

\title{
THE CASE OF SUCCESSFUL ELIMINATION OF ATRIAL FIBRILLATION USING CRIOMODIFICATION OF COX MAZE PROCEDURE AFTER INEFFECTIVE THORACOSCOPIC PULMONARY VEIN ISOLATION AND RADIOFREQUENCY ABLATION OF THE CAVATRICUSPIDAL ISTHMUS
}

\author{
L.A. Bockeria, S.Yu. Serguladze, B.I. Kvasha, D.Ya. Khinchagov
}

Bakoulev National Medical Research Center for Cardiovascular Surgery, Rublevskoe shosse, 135, Moscow, 121552, Russian Federation

Leo A. Bockeria, Dr. Med. Sc., Professor, Academician of RAS, Director of the Center; Sergey Yu. Serguladze, Dr. Med. Sc., Senior Researcher, Deputy Head of Department; Boris I. Kvasha, Cand. Med. Sc., Junior Researcher, E-mail: Boris_mma@mail.ru; Dzhumber Ya. Khinchagov, Cand. Med. Sc., Anesthesiologist 
of drug-resistant AF. According to the world literature, a stable sinus rhythm after catheter procedures is noted for 61-89\% of patients when previously antiarrhythmic therapy is ineffective. The efficacy of thoracoscopic surgery in patients with paroxysmal AF is $83-89 \%$, which correlates with the effectiveness of catheter techniques. The disadvantage of the thoracoscopic approach is the possibility of applying ablative lines only in the left atrium. Recently, an intervention procedure in the right atrium is being added to the thoracoscopic operation, which makes it more efficient. Unfortunately, this scheme of operations is not able to provide freedom from AF in long-term to all patients. A special feature of the described clinical case is the radical effective elimination of drug-resistant $A F$, previously unsuccessfully treated with the use of interventional and catheter techniques, after the cryomodification of the maze procedure on the open heart.

Keywords: atrial fibrillation; maze procedure; radiofrequency ablation; minimally invasive thoracoscopic surgery.

\section{Введение}

Фибрилляция предсердий (ФП) - наиболее распространенная аритмия, которая встречается у $1-2 \%$ населения и является значительным бременем для здравоохранения, связанным со смертностью, заболеваемостью и 5-кратным увеличением риска развития инсульта [1].

Эволюция хирургических методов лечения ФП позволила добиться эффективного устранения любых ее форм. Для пациентов, не поддающихся лечению антиаритмическими препаратами, были введены нефармакологические вмешательства, включая чрескожную эндокардиальную катетерную аблацию и минимально инвазивную торакоскопическую хирургическую аблацию. Краеугольным камнем эндокардиального подхода является изоляция устьев легочных вен, при этом дополнительные линии аблации выбираются в зависимости от каждого клинического случая. Эффективность катетерной процедуры при соблюдении этих условий в сроки наблюдения до 5 лет по данным разных авторов колеблется в пределах 61-89\% [2].

Минимально инвазивный торакоскопической подход представляет собой эпикардиальную аблацию на работающем сердце с использованием биполярной радиочастотной энергии. У пациентов с пароксизмальной формой ФП эффективность торакоскопической операции составляет 83-89\%, что сопоставимо с данными катетерных методик [3, 4]. В то же время у больных с персистирующей формой ФП, расширенным левым предсердием (ЛП) и гипертонической болезнью торакоскопическая хирургическая аблация превосходит катетерную аблацию в достижении свободы от ФП через 12 мес наблюдения, согласно данным двухцентрового рандомизированного исследования FAST [5]. Вместе с тем исследователи отмечают, что частота хирургических осложнений при торакоскопической процедуре выше, чем при катетерной [6].
Однако «золотым стандартом» в лечении ФП остается хирургическая операция «Лабиринт III» благодаря своей эффективности, которая в сроки наблюдения более 10 лет составляет 89-92\% [7]. Из-за сложности выполнения, длительного искусственного кровообращения (ИК) и вероятности развития хирургических осложнений данная операция претерпела множество модификаций. Модификация с использованием холодовой аблации позволила заменить традиционную технику «разрез-шов», применяемую в операции «Лабиринт III», на создание линии электрической изоляции в миокарде с помощью криоэнергии, что значительно упростило технику операции и уменьшило длительность ИК [8].

Подгрупповой Байесовский сетевой метаанализ, включивший 16 опубликованных рандомизированных исследований, выявленных в 6 базах данных, в котором впервые провели сравнение безопасности и эффективности различных источников энергии для хирургической аблации ФП, показал, что подход «разрез-шов» связан с более высокими показателями летальности по сравнению с другими лабиринтными процедурами, в рамках которых используются радиочастотные (РЧ), криоэнергетические и микроволновые источники энергии, в то время как распространенность синусового ритма после 12-месячного наблюдения была аналогична при подходе «разрез-шов» и хирургических методиках с применением различных источников энергии [9]. Данные долгосрочных исследований доказывают, что криоаблация не уступает применению радиочастотной энергии в эффективности и безопасности, при этом объединенные результаты метаанализа, включившего 7195 пациентов (2863 с криоаблацией, 4332 с радиочастотной аблацией), показали $65,4 \%$ свободы от ФП или предсердной тахикардии после применения холодовой аблации в срок наблюдения 12 мес (ОР $1,05 ; 95 \%$ ДИ $0,98-1,13 ; p=0,159)$ [10].

Представленный клинический случай демонстрирует успешное устранение ФП с помощью 
криомодификации операции «Лабиринт» у пациента с длительно персистирующей формой аритмии, который перенес торакоскопическую изоляцию устьев легочных вен и радиочастотную аблацию (РЧА) кавотрикуспидального перешейка.

\section{Клинический случай}

Пациент X., 41 год, был госпитализирован с жалобами на перебои в работе сердца, ритмичное и неритмичное сердцебиение, учащение ритма до 180 уд/мин, непереносимость физических нагрузок.

Из анамнеза: пациент считает себя больным с 18 лет, когда его стали беспокоить приступы учащенного неритмичного сердцебиения, которые купировались внутривенным введением антиаритмических препаратов.

Учитывая персистирующий характер аритмии, больному была успешно выполнена торакоскопическая изоляция устьев легочных вен и РЧА каватрикуспидального перешейка. Из антиаритмической терапии пациент длительное время принимал сотагексал. Синусовый ритм сохранялся в течение 1 мес, далее приступы аритмии участились и стали носить затяжной характер. Дозы сотагексала были увеличены до 320 мг/сут - с временным эффектом.

В течение последующих 2 лет состояние больного постепенно ухудшалось, синусовый ритм медикаментозно не восстанавливался. Пациенту было выполнено электрофизиологическое исследование и эндокардиальная РЧ-изоляция устьев легочных вен без эффекта. Из антиаритмической терапии (ААТ) больной получал кордарон, сотагексал - с относительным эффектом.

Спустя полгода пациент отметил неэффективность ААТ с появлением симптоматической тахисистолии, после чего был госпитализирован в отделение хирургического лечения тахиаритмий для устранения аритмии.

Электрокардиография (ЭКГ): ФП с частотой желудочковых сокращений (ЧЖС) 98 уд/мин.

Суточное мониторирование ЭКГ по Холтеру: основной ритм - ФП с ЧЖС 84-178 уд/мин.

Трансторакальная эхокардиография (ЭхоКГ): ЛП увеличено $(5,1 \times 5,6$ см), правое предсердие (ПП) увеличено $(4,3 \times 5,8$ см); митральный клапан (MK) - регургитация 2-3 ст., миксоматозная дегенерация створок; трикуспидальный клапан (ТК) - регургитация 2 ст.; левый желудочек не увеличен - конечный систолический размер
3,2 см, конечный диастолический размер 5 см, конечный диастолический объем 117 мл, конечный систолический объем 42 мл, ударный объем 75 мл, фракция выброса (по формуле Тейхольца) $64 \%$.

Компьютерная томография ЛП: объем 180 мл, анатомия легочных вен не изменена.

Результаты клинических и биохимического анализов крови и мочи - без отклонений от нормы.

Учитывая неэффективность предыдущих попыток устранения ФП, а также высокую симптоматичность заболевания, было принято решение о выполнении операции на открытом сердце.

\section{Протокол операции}

Пациент доставлен в операционную на ритме ФП с ЧЖС 140 уд/мин. Выполнена срединная стернотомия. Отмечается выраженный спаечный процесс. Кардиолиз. Канюляция аорты, раздельная канюляция полых вен. ЛП дренировано через правую верхнюю легочную вену. По стандартной методике начато ИК с гипотермией $28^{\circ}$. Далее проведена антеградная кардиоплегия раствором кустодиол (1500 мл) в корень аорты. Вскрыто ПП, при ревизии отмечается выраженный фиброз эндокарда как следствие предыдущих РЧ-воздействий. Во время кардиоплегии проведено два криовоздействия в правом ПП: 1) от фиброзного кольца ТК и основания ушка ПП до crista terminalis; 2) в области правого нижнего перешейка сердца (рис. 1).

Далее создан расширенный двухпредсердный доступ к МК через межпредсердную перегородку и купол ЛП. Также отмечается выраженный фиброз эндокарда ЛП от проведенных ранее РЧ-воздействий. В ЛП нанесено 4 криовоздействия (рис. 2): 1) проведена линия вдоль коронарного синуса; 2) единым блоком изолированы правые легочные вены; 3) единым блоком изолированы левые легочные вены; 4) изолировано основание ушка ЛП с линией к фиброзному кольцу МК. Все криовоздействия наносились эндокардиально, с помощью генератора для холодовой аблации ATS CryoMaze, использовался режим $-95 \mathrm{C}^{\circ}$ в течение 2 мин на каждое воздействие.

При ревизии ТК: фиброзное кольцо расширено, коаптация нарушена, при гидропробе отмечается недостаточность. Выполнена шовная пластика ТК ниткой пролен 4/0 на трех прокладках на буже № 28. Гидропроба показала хорошую запирательную функцию ТК. 


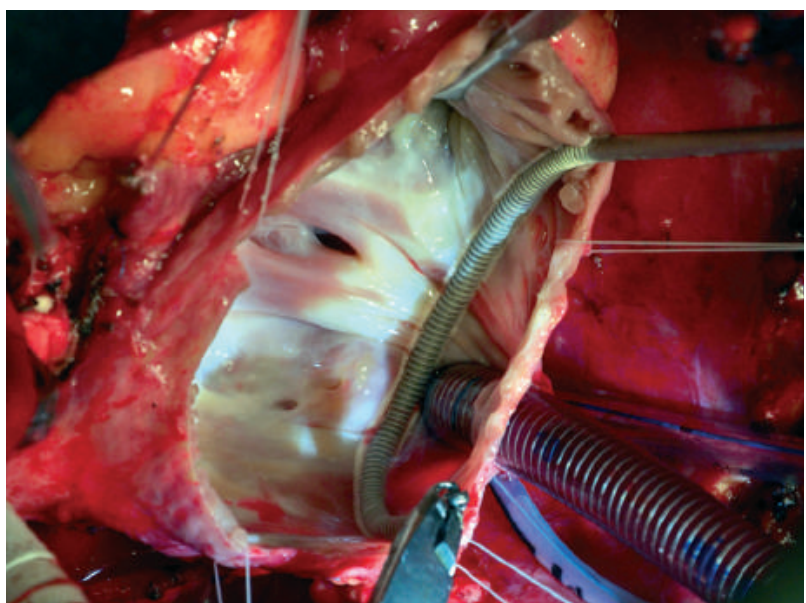

Рис. 1. Криовоздействие в правом предсердии (интраоперационное фото)

При ревизии МК: фиброзное кольцо расширено, створки не коаптируют, выраженный миксоматоз с пролабированием обеих створок, обнаружен отрыв хорд от сегмента А2 передней створки МК. При гидропробе отмечается значительная недостаточность. Клапан иссечен, и в проекцию МК имплантирован на 15 П-образных швах механический протез «Карбоникс-1» № 28. Купол ЛП и межпредсердной перегородки ушит двурядным швом. Ушко ЛП перевязано лавсановой нитью со стороны перикарда. Ушито ПП. Проведено согревание пациента. Отпущены полые вены. Осуществлено заполнение камер сердца с профилактикой воздушной эмболии. Отпущена аорта. Сердечная деятельность восстановлена 1 разрядом дефибриллятора. Узловой ритм с частотой сердечных сокращений (ЧСС) 40 уд/мин. Подшиты временные электроды: 2 к миокарду правого желудочка и 2 к миокарду ПП. Налажена временная наружная электрокардиостимуляция в физиологическом режиме (DDD) с частотой 90 уд/мин.

Стабилизация гемодинамики. Завершение ИК, деканюляция. Тщательный гемостаз. Введены дренажи в переднее средостение, правую и левую плевральные полости. Грудина сведена стальными проволочными швами № 7. Выполнено послойное ушивание послеоперационной раны. Наложена асептическая повязка. Пациент переведен в ОРИТ на ритме от электрокардиостимуляции с ЧСС 90 уд/мин (собственный ритм предсердный с ЧСС 65 уд/мин). Время пережатия аорты составило 77 мин, время ИК - 128 мин.

Послеоперационный период протекал без особенностей. По данным ЭхоКГ: фракция выбро-

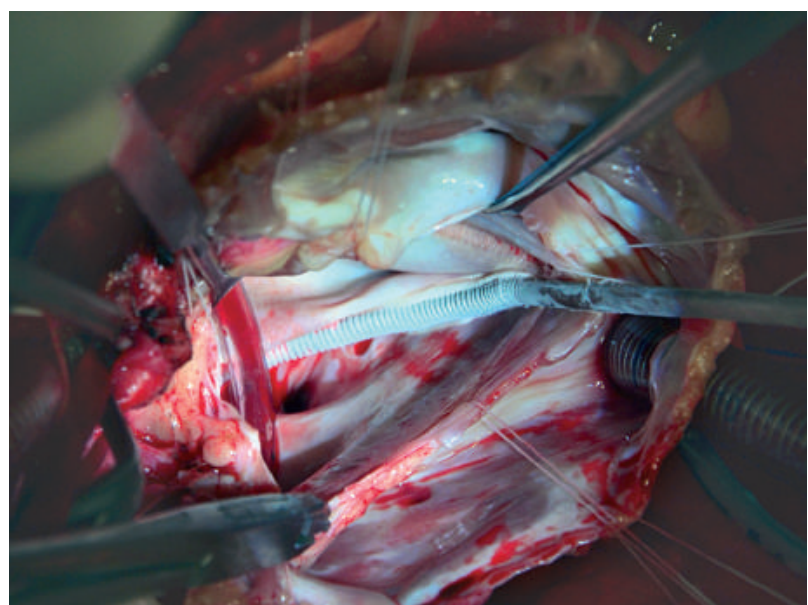

Рис. 2. Криовоздействие в левом предсердии (интраоперационное фото)

са 55\%; пиковый градиент давления на МК 12 мм рт. ст., средний градиент 4 мм рт. ст.; на ТК недостаточности нет; жидкости в полости перикарда нет. На 7-е сутки после операции проведено суточное мониторирование ЭКГ по Холтеру: основной ритм предсердный со средней ЧСС 69 уд/мин, максимальная ЧСС 107 уд/мин, минимальная ЧСС 46 уд/мин; значимых пауз ритма не выявлено.

На 12-е сутки в удовлетворительном состоянии пациент был выписан под наблюдение кардиолога по месту жительства. Медикаментозная терапия при выписке: варфарин, амиодарон, верошпирон.

Через 6 мес выполнено плановое холтеровское мониторирование ЭКГ, по результатам которого: основной ритм синусовый со средней ЧСС 58 уд/мин; пауз ритма, эпизодов желудочковой тахикардии, куплетов бигеминии и тригеминии не зарегистрировано. Принято решение отменить АAT.

\section{Обсуждение}

На сегодняшний день не вызывает сомнения тот факт, что хирургические методы лечения наиболее эффективны для восстановления и удержания синусового ритма у пациентов с ФП. Однако катетерная эндокардиальная или торакоскопическая эпикардиальная РЧ-изоляция легочных вен показывает свою высокую эффективность у больных с пароксизмальной формой ФП и меньшую эффективность при персистирующих формах ФП. Популяционные исследования установили, что у $75 \%$ пациентов имеются персистирующая и постоянная формы ФП [11]. Это означает, что только изоляция легочных вен 
в таких случаях будет малоэффективна. Выполнение аблации торакоскопическим доступом по схеме Dallas lesion set, которая имитирует левостороннюю часть процедуры «Лабиринт III», достигает эффективности 90-96\% [12]. Минусом данной схемы по сравнению с оригинальной операцией «Лабиринт» является наличие аблационных линий только в ЛП. Но этот недостаток легко поправим, если к торакоскопическому левостороннему этапу добавить интервенционную процедуру в ПП.

Прием прямых антикоагулянтов для выполнения интервенционной процедуры затрудняет одномоментное гибридное вмешательство из-за высокого риска геморрагических осложнений. Поэтому данная схема требует двухэтапного подхода, разнесенного по времени, что влечет за собой значительное увеличение стоимости процедуры.

Таким образом, криомодификация операции «Лабиринт» позволяет нанести аблационные линии одновременно в правом и левом предсердиях и остается наиболее эффективным способом восстановления и удержания синусового ритма у пациентов с любой формой ФП [8]. Это достигается за счет фрагментации ткани предсердий, делающей невозможным существование ФП вне зависимости от ее вида, а при наличии клапанной патологии также позволяющей одномоментную ее коррекцию.

\section{Заключение}

Существует множество различных подходов к интервенционному и хирургическому лечению персистирующих форм, учитывающих все известные механизмы ФП. Такое многообразие говорит о том, что на сегодняшний день нет идеального стандарта в лечении данной патологии. Приведенное нами клиническое наблюдение демонстрирует случай эффективного применения многоэтапного подхода в лечении ФП, который включал торакоскопическую изоляцию устьев легочных вен, РЧА каватрикуспидального перешейка и хирургическую криоаблацию в условиях ИК. Основные результаты Байесовского рангового анализа вероятностей показали, что пациенты, у которых применен хирургический подход с дополнительными аблациями, значительно чаще находятся на синусовом ритме при сроке наблюдения более 1 года, а использование источников энергии для хирургического лечения ФП в качестве альтернативы традиционному подходу «разрез-шов» связано с увеличением показателей долговременного удержания синусового ритма [9].

\section{Конфликт интересов}

Конфликт интересов не заявляется.

\section{Библиографический список [References]}

1. Colilla S., Crow A., Petkun W., Singer D.E., Simon T., Liu X. Estimates of current and future incidence and prevalence of atrial fibrillation in the U.S. adult population. Am. J. Cardiol. 2013; 112 (8): 1142-7. DOI: 10.1016/j.amjcard.2013.05.063

2. Weerasooriya R., Khairy P., Litalien J., Macle L., Hocini M., Sacher F. et al. Catheter ablation for atrial fibrillation: are results maintained at 5 years of follow-up? J. Am. Coll. Cardiol. 2011; 57 (2): 160-6. DOI: $10.1016 / j . j a c c .2010 .05 .061$

3. De Maat G.E., Pozzoli A., Scholten M.F., Van Gelder I.C., Blaauw Y., Mulder B.A. et al. Long-term results of surgical minimally invasive pulmonary vein isolation for paroxysmal lone atrial fibrillation. Europace. 2015; 17 (5): 747-52. DOI: 10.1093/europace/euu287

4. Wang S., Liu L., Zou C. Comparative study of video-assisted thoracoscopic surgery ablation and radiofrequency catheter ablation on treating paroxysmal atrial fibrillation: a randomized, controlled short-term trial. Chin. Med. J. (Engl.) 2014; 127 (14): 2567-70.

5. Boersma L.V., Castella M., van Boven W., Berruezo A., Yilmaz A., Nadal M. et al. Atrial fibrillation catheter ablation versus surgical ablation treatment (FAST): a 2-center randomized clinical trial. Circulation. 2012; 125 (1): 23-30. DOI: 10.1161/CIRCULATIONAHA.111.074047

6. Phan K., Phan S., Thiagalingam A., Medi C., Yan T.D. Thoracoscopic surgical ablation versus catheter ablation for atrial fibrillation. Eur. J. Cardiothorac. Surg. 2016; 49 (4): 1044-51. DOI: $10.1093 /$ ejcts/ezv180

7. Ballaux P.K., Geuzebroek G.S., van Hemel N.M., Kelder J.C., Dossche K.M., Ernst J.M. et al. Freedom from atrial arrhythmias after classic maze III surgery: a 10-year experience. J. Thorac. Cardiovasc. Surg. 2006; 132 (6): 1433-40. DOI: 10.1016/j.jtcvs.2006.06.048

8. Бокерия Л.А., Бокерия О.Л., Биниашвили М.Б., Кваша Б.И. и др. Хирургическое лечение фибрилляции предсердий с помощью криомодификации операции «Лабиринт». Сердечно-сосудистые заболевания. Бюллетень НЦССХ им. А.Н. Бакулева РАМН. 2011; 12 (S6): 79.

[Bockeria L.A., Bockeria O.L., Biniashvili M.B., Kvasha B.I. et al. Surgical treatment of atrial fibrillation with the help of cryomodification of Cox-Maze. Cardiovascular Diseases. Bulletin of Bakulev Center for Cardiovascular Surgery. 2011; 12 (S6): 79 (in Russ.).]

9. Phan K., Xie A., Kumar N., Wong S., Medi C., La Meir M., Yan T.D. Comparing energy sources for surgical ablation of atrial fibrillation: a Bayesian network meta-analysis of randomized, controlled trials. Eur. J. Cardiothorac. Surg. 2015; 48 (2): 201-11. DOI: 10.1093/ejcts/ezu408

10. Chen Y.H., Lu Z.Y., Xiang Y., Hou J.W., Wang Q., Lin H., Li Y.G. Cryoablation vs. radiofrequency ablation for treatment of paroxysmal atrial fibrillation: a systematic review and meta-analysis. Europace. 2017; 19 (5): 784-94. DOI: 10.1093/europace/euw330

11. Zoni-Berisso M., Lercari F., Carazza T., Domenicucci S. Epidemiology of atrial fibrillation: European perspective. Clin. Epidemiol. 2014; 6: 213-20. DOI: 10.2147/CLEP.S47385

12. Sirak J.H., Schwartzman D. Interim results of the 5-box thoracoscopic maze procedure. Ann. Thorac. Surg. 2012; 94 (6): 1880-4. DOI: 10.1016/j.athoracsur.2012.06.010

Поступила 29.05.2018 Принята к печати 11.06.2018 